\title{
Location Criteria Relevant for Sustainability of Social Housing Model
}

\author{
Nataša Petković-Grozdanović ${ }^{1, *}$, Branislava Stoiljković ${ }^{1}$ and Mikhail Shubenkov ${ }^{2}$ \\ ${ }^{1}$ University of Niš, Univerzitetski trg 2, Niš, 18000, Serbia \\ ${ }^{2}$ Moscow Institute of Architecture (State Academy), Rozhdestvenka, 11, 107031, Moscow, Russia
}

\begin{abstract}
Social housing models, which had began to develop during the last century, for their only objective had a need to overcome the housing problems of socially vulnerable categories. However, numerous studies have shown that these social categories, because of their low social status, are highly susceptible to various psychological and sociological problems. On the other hand a low level of quality, which was common for social housing dwellings, has further aggravated these problems by initiating trouble behaviours among tenants, affecting social exclusion and segregation. Contemporary social housing models are therefore conceptualized in a way to provide a positive psycho-sociological impact on their tenants. Therefore the planning approach in social housing should be such to: support important functions in daily life routines; promote tolerance and cooperation; influence on a sense of social order and belonging; affect the socialization of the tenant and their integration into the wider community; and improve social cohesion. Analysis of the influential location parameters of immediate and wider social housing environment strive to define the ones relevant to the life quality of social housing tenants and therefore influence on the sustainability of social housing model.
\end{abstract}

\section{Introduction}

The long-standing building tradition of the social housing complex, conceived on the idea of mass industrial construction, had resulted in spatial and social segregation, which further generated the various problems within these complexes. Numerous studies, some of which date back at the end of the last century, launched the question of the influence that complexes' of social housing and theirs immediate surrounding has on the level of social exclusion within their tenants (Newman 1970, Jacobs, 1961; Wilson, 1996; Munch, 2009). Some authors believe that precise urban and architectural approach in the construction of social housing complex had originated high level of different behaviour problems within these complexes (Jacobs, 1961; Newman, 1970; Petrović, 2004; Bolt, 2009), such as: early school abandoning, alcohol and drugs abuse, bullying and etc. Such housing environment further affected the population of these complexes, which resulted with a complete inefficiency of these housing models.

*Corresponding author : natasapetkovic83@gmail.com 
These researches have shown that social housing cannot be reduced only to the provision of housing as a plane shelter. In the contemporary social housing models, the manner of their spatial positioning and organization; arrangement of the specific housing structures within residential area, and the quality of facilities intended for social housing therefore is increasingly associated, not just with urban or architectural planning, but also with social planning. In addition to achieve adequate housing and living standard, new social housing models tend to provide favourable sociological climate to their tenants as well. Socialization of the tenants by initiating social interactions within tenants of the social housing complex and its wider surrounding influences on the sense of belonging and safety of the tenants and encourage their integration within the neighbourhood.

Regarding this, it's not surprising that the basis of contemporary social housing models is relied on the manner how the urban planning of social housing complexes is managed, both from the aspects of positioning the social housing structures within the urban core and the belonging residential areas, and terms of planning and organizing such complex within their micro environment. However in urban planning approach of the new social housing models the emphasis must not be placed only on the quality of housing within those dwellings; on contrary the overall housing quality of social housing models has to be viewed as well through the sociological impact that these complexes have on the individual wellbeing and on society in general.

\section{Socio-spatial short comings evidented in the existing social housing estates}

The analysis of the examples of international practice in the construction of social housing estates had shown some common problems aroused during their exploitation time, which led to the conclusion of the certain common shortcomings:

- Locations of the social housing estates often were not understand in the context of existing urban matrix and its relationship with the surrounding urban fabric. As a consequence, large social housing estates were built in remote locations. Conceived like isolated urban islands, the position of these complexes had caused the creation of social segregation, which continued to generate a numerous problems within these residential areas (Jacobs, 1961; Newman 1970).

- The majority of social housing complexes build in the twentieth century was conceived and designed in a way to provide a cheap dormitory, all based on the idea of mass-industrial production (Jacobs, 1961; Newman 1970). The emphasis was on the quantity - building as much housing units under most economically favourable conditions. In such circumstances a very small amount of attention were paid on the housing quality and the individual needs of future tenants.

- Architectural uniformity arising from the mass-industrial construction was one of the main features of social housing complex (Jacobs, 1961; Newman 1970).

- High degree of social segregation - Different forms of problematic behaviour within these neighbourhoods (Jacobs, 1961; Newman 1970; Milić, 2006; Munch, 2009), have influenced on the sociological isolation of tenants of these areas.

Social housing models with detected shortcomings mentioned above, in the practice had given extremely negative results. Conceived on such principles, designed entirely for the use of social housing, became extremely unpopular places to live. As the residents of these areas have not been able to meet their basic housing needs, the high percentage of the apartments in these complexes was abandoned by their tenants. A large percentage of unoccupied units had influenced not only the facilities within social housing complexes but also had resulted in deterioration of both near and wide environmental surrounding. 


\section{Criteria for evaluation socio-spatial quality}

Identified shortcoming have allowed more detailed assessment of the needs that social housing models should meet and also the necessary characteristics of the area within social housing complexes are planning to be located. In terms of immediate living environment in order to ensure higher housing and living quality, better integration of the social housing tenants within the housing areas; and the achievement of higher spatial and social cohesion is necessary in order to overcome the problems and shortcoming detected within existing social housing complexes.

The aim of this study, on the basis of observed shortcoming, is to define relevant criteria for the quality of social housing and the sustainability of social housing models, through the analysis of a large number of influential factors prevailing in the immediate and wider environment.

The supposed measurable aspects that largely influence the quality of housing and living environment and thus the value and the sustainability of social housing models are:

- Position of the social housing complex to the urban city core;

- Supporting facilities within residential area;

- Common spaces intended for use by the tenants of the social housing complexes;

- Heterogeneity of the social housing complex and its wider environmental surrounding.

As the problems, detected on the existing social housing complexes, show a close correlation between physical (position, manner of the planning and design of the complex social housing) and sociological (problematic forms of behaviour, levels of social exclusion, the degree of social segregation) aspects, this study analysis each criterion in comparison to both aspects, and strive to determinate the link between them.

\section{Influential factors}

The paper further analyses and evaluates the qualitative characteristics of alternative social housing solutions for individual spatial criteria.

\subsection{Position of the social housing complex to the urban city core}

The proximity to the urban city core, the distance from business, commercial, cultural and educational facilities, certainly affects the attractiveness of some location. However residential satisfaction surveys carried on the numerous residential areas show that this is not a crucial factor (Kauko, 2006; Geraedts \& Voordt, 2007; radovi sa SCI). When it comes to residential satisfaction with environmental surrounding it mainly depends on the subjective attitude of potential users.

Conducted researches have shown that the proximity of residential area to the central city core is not the determining factor when it comes to the quality of the housing complex location (Kauko, 2006; Geraedts \& Voordt, 2007). The research carried on in Finland (Kauko, 2006) had shown that within residential areas that were well infrastructural equipped and without difficult access, the residents have far more valued the quality of the living environment and the social climate.

However, while the above research shows that high frequency and the availability of the public transport are to a lesser extent when it comes to the choice of the housing environment, and that it is not of a crucial importance when it comes to successful of the housing complex realization, the research conducted on mono-centrically residential areas (Kauko, 2006) had show that the proximity to the urban city core, the availability of main 
traffic ruts and the frequency of the public transportation, were registered as a very important parameters, almost as important as the quality of living space.

Residential areas which are remote from the urban city core, however, do not necessarily suffer from the lack of housing quality. The example of the social housing complex Columbia Point in Boston, USA, shows that even spatially isolated and cut off from the rest of the urban core, have initiated even a greater sense of belonging among their tenants (Thebaud et al., 2008). Tenants have been faced to one another, which resulted in groups formed for cleaning, maintaining and interior decorating of the buildings, as well as their immediate environment. The positive affects was also noticed among parents who helped each other in babysitting.

Selection of the location directly dictates the initial cost of construction. As the economic sustainability is a basic prerequisite for the development of social housing models, the position of the complex intended for social housing is not possible to be at the "attractive" city locations. Primarily, for the location of such complex should be chosen those sites that could meet the basic tenants' needs; to reach the necessary facilities within a reasonable period of time, having in mind that among the tenants of social housing complexes very likely a lot of them who don't own a car. Therefore it is highly recommended that social housing complexes should be planned within the areas of central economic value (Fishman, 2004; Milic, 2006; NRIF, 2015). If this approach is not possible and requires the construction of social housing complex in a remote location, it is necessary to be positioned in the part with the higher service standard (Milić, 2006). This mainly refers to the position of social housing complex in suburban locations, which is very often the case in the current social housing models in Serbia. In such circumstances it is desirable to locate these complexes in central part of the area, or close to the amenities and service facilities.

\subsection{Supporting facilities within residential area}

Analysis of the previous criterion showed that most favourable areas are the ones with the higher quality of living environment and within walking distance to the service facilities, shops, workplace or social contents. But this factor precisely is the crucial in terms of economic viability of the social housing models. From the economic aspect, planning the social housing complex within a highly equipped residential area is unsustainable. In general, for housing to be affordable, it cannot count on high functional location standard, but rather the minimum; concerning the supply, education, child and health care and public transportation.

Mixed-use areas, which in their settings include some production or storage facilities, certain types of light industry or office spaces, are more suitable location in comparison to undeveloped suburbs (Milić, 2006; DSCI, 2015). Social housing can be easily integrated into those areas, because there are already a large variety of spatial and physical structures. In addition, introduction of the housing in these areas has the influence on their live cycle, because the hour cycles are complementary. Thus, the area maintains a certain level of necessary activities for 24 hours. Higher frequency during the day, supported from the business services, reduces the feeling of isolation among tenants and affects the sense of security; while the housing gives a human dimension to the area and provides an additional frequency after the working hours (DSCI, 2015). However it is necessary to combine such activities that are compatible with housing.

The potential working place for the unemployed and their relative proximity to the place of residence, reduced transportation costs, higher social inclusion of the residents by using the location support amenities are only some of the aspects that might have positive effect on the sociological component of social housing models. 
In addition, the planning of social housing within mixed-use areas can provide a completely new dimension of the model sustainability, as it allows the use of some innovative approaches, such as: extensions of non-housing structures with additional housing units or conversion of industrial or warehouse buildings. Beside the economic and environmental sustainability, this approach has one additional advantage; it keeps the "identity" of space which has a positive influence on the sense of belonging.

\subsection{Common spaces intended to be used by tenants of the social housing complexes}

Due to economic circumstances the social housing units are very reduces in their size, therefore the existence of common spaces which could be used by the tenant, affects the housing quality as provides additional space that can be used by the tenants for recreation, interaction, playing and etc. Barring in mind obvious problems of social exclusion among the tenants of social housing complexes, in addition to functions mentioned above, the common areas should be organized in a way to encourage social interaction both between the tenants of the social housing complex, and with the residents of surrounding housing areas. By initiating social activities within the spaces intended for common use by the tenants, it is possible to encourage socialization and facilitate theirs' social inclusion, both in the immediate residential surrounding and in society in general (Unger \& Wandersman, 1985; Forrest \& Kearns, 2001; Huang, 2006; Cattell et al., 2008; Dai, 2011). The existence of playground, for example, besides influencing on the interaction among children which can encourage them to make friendship with one other, can also influencing the creation and development of the contacts among adults who are monitoring them (Huang, 2006; Faridan, 2013). Those adults already have a common topic - the children they are supervising, as well as numerous similar experiences that are sharing. Furthermore, the same parents are likely to meet at the same playgrounds often, and thus have the opportunity to develop real relationships. (Figure 1)
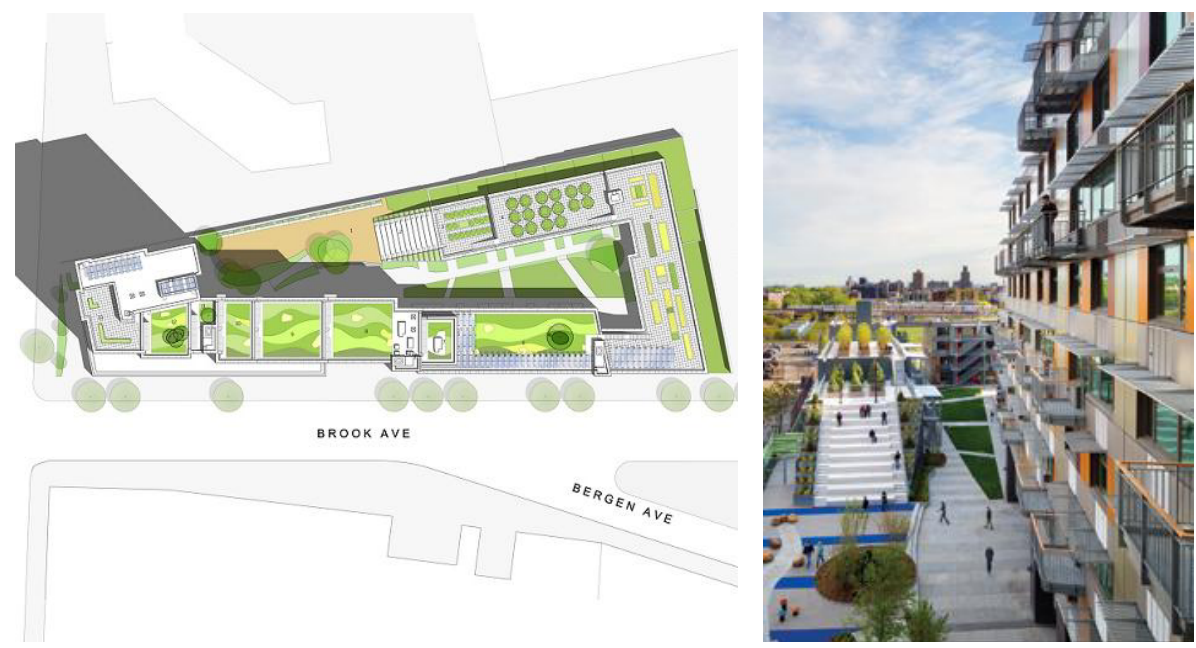

Fig. 1. Social housing complex Via Vrede Bronx, New York, USA. A dynamic garden serves as the organizing element for the community.

Secondly, for social housing complexes, due to the limited mobility of their inhabitants (elderly, people with poor health, people with disabilities, families with children and households with very low incomes) location and proximity of the common areas to the 
housing complex is a prerequisite for the development of social activities and social networks among the tenants (Dai, 2011; Ćetković, 2014).

The majority of free time of the beneficiaries of social housing complexes is related to the local contents. Therefore it is necessary that the facilities intended for the joint use by the tenants find within the complex of social housing, and if this is not possible, in their vicinity (Figure 1). If in the immediate vicinity of the site planned for the construction of social housing such facilities do not exist it is necessary to choose such location that is close to the spaces that can potentially be organized as common areas, with a minimum of intervention in terms of rehabilitation and reuse.

However, the physical existence and proximity to such areas are often not sufficient to conduct social interaction between the tenants. Researches show that the role of common open areas, to initiate social contacts among residents, largely depends on the physical features of the interactional areas.

The design of these areas and the existence of street furniture have been identified as very important elements for the quality of common open areas in order to achieve social interaction. Adequately planned and equipped common areas are attractive to users and affect the longer staying, and thus increase the possibility to develop social activities among tenants (Gehl, 1986; Carr et al., 1992). The provision of greenery in common open areas increases the opportunity for social activities (Kweon et al., 1998; Sullivan et al., 2004), and enhance social bonding among residents (Coley et al., 1997; Skjaeveland and Garling, 1997; Huang 2006). Interactional spaces should be welcoming and accessible to everyone. That means that it has to be in a place they can easily get to, and that they feel welcome when they get there. The characteristics of good spaces for interaction are that they provide reasons for people to go there; reasons to linger once they're there; safety and security; and a welcome and accessibility to all. All of these are, to a greater or lesser extent, dependent on design.

\subsection{Heterogeneity of the social housing complex and its wider environmental surrounding}

Although it is recommended that social housing complexes should be low or maximum medium density housing, construction of homogeneous complexes of social housing, both in structural and shaping sense, is abandoning. The recommendations concerning urban planning and design of the social housing complexes highlight the need for mixing different structure types, using diversity of housing concepts and including various physical housing structures (Jacobs, 1961; Newman, 1970; Milić, 2006).

The variety of housing structures, with different density area mixture, allow the development of a different housing forms and shapes, which results in a dynamic of the residential area. This approach aims to avoid the monotony that is considered to be one of the main shortcomings of the existing social housing complex.

Whenever it's possible it should strive toward the formation of individual housing units that are directly connected with the surrounding environment. Semi-detached houses, row houses or housing units in the form of duplexes with direct connection to the ground are a good solution, as they provide the necessary individuality to the households; and on the other hand locate the residents to be in direct correlation with the surroundings.

The individual housing units should be designed to have the small front yard, while the back yard should be larger in size and used as an open area that in summer should take a part of the everyday activities (Newman, 1970).

If this approach is not possible, it is desirable to combine family and low-rise and lowdensity multifamily housing structures (Jacobs, 1961; Newman, 1970; Milić, 2006; Radovic, 2014). Higher dwellings and higher density areas can reduce the positive aspects 
of this approach, which main aim is to prevent social exclusion of the tenants. The low-rise housing is preferably in terms of the better tenant's integration in the surrounding environment and the higher degree of social cohesion. The closeness to the surroundings affects the residents of these facilities to feel less isolated.

The possibility for parents to monitor their children, who are playing outside, strait from their homes, gives a greater sense of security. Relating older persons to the events in the immediate surroundings of their living space, on the street or in the neighbourhood, reduces their isolation.

All this have a positive effect on the tenants' satisfaction, encourage a sense of community within the residential area and contributes to better social climate in the area. In addition to the heterogeneity of the social housing complex itself, a certain level of heterogeneity within the wider housing areas is also mandatory (Figure 2).

Groups of multiple dwellings, intended for social housing, located within the complexes only intended for this type of housing, has proven to be extremely inefficient. In order to prevent spatial segregation the very important part of the planning is the proper positioning or rather the integrating of social housing complex in the existing urban matrix. Fragmental integration of various singular locations and combination of small group of social housing with other types of housing within residential areas of slightly higher standards are more favourable in terms of space and social segregation (Milić, 2006). (Figure 2)
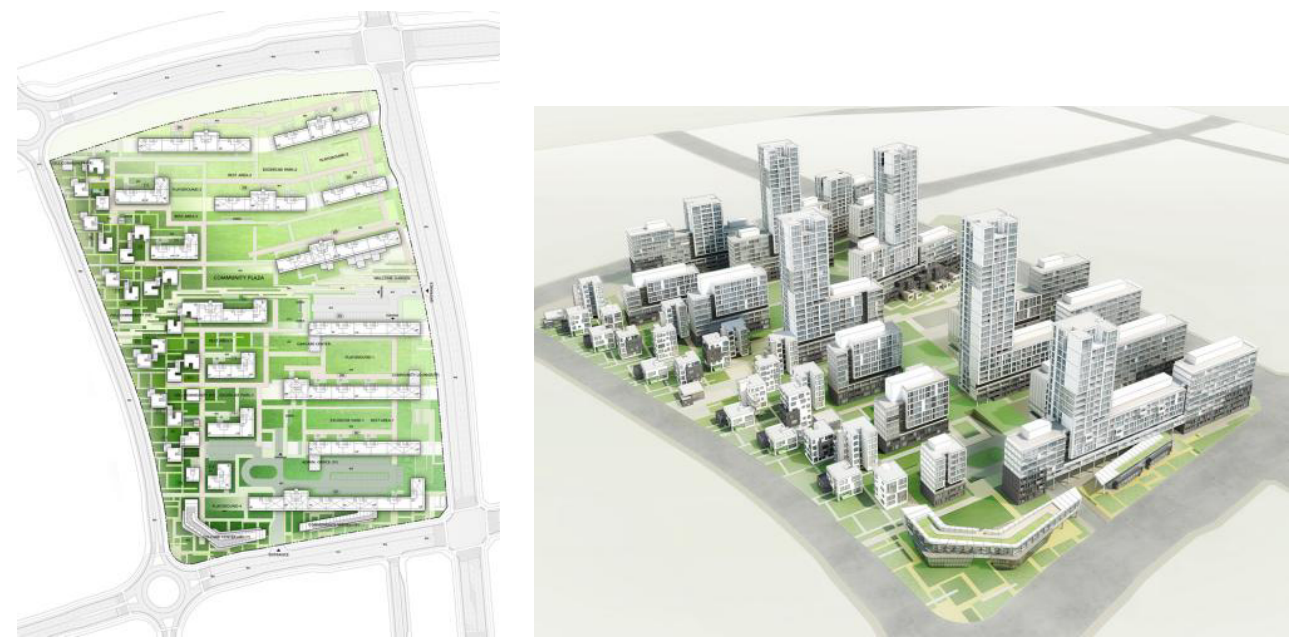

Fig. 2. Senjong 2-2 M2 housing complex Bronx, New York, USA. A multi-dimensional housing scheme with open organization of various types of building units that celebrates the diversity of residents.

\section{Conclusions}

The social housing models, in addition to their main demand to provide decent housing conditions, should also have positive effects on the sense of belonging among their tenants and social inclusion, through the stimulation of social competence and participation. These models should also provide support for the important everyday functions. By maintaining the tolerance, cooperation, sense of social order and belonging, these models should influence positively of the social cohesion in the social housing complexes and wider residential surrounding.

As tenants of these complexes are various socially vulnerable groups, which are more likely to spent their free time within the local residential area, the main focus of the social 
housing models' should be to find adequate spatial housing solutions that would have the potential to contribute to the social inclusion of the tenants and the level of social cohesion in the housing community.

In order to prevent the stigmatization of those areas, future complexes of social housing should meet the following (whether if it is a new dwelling construction or the revitalization of old or abandoned complex). 1) They need to be adequately positioned within the existing urban matrix and in the immediate vicinity of the necessary service facilities. If this is not the case, during the process of social housing complex planning, it is essential to anticipate the introduction of new service facilities, either by integrating them into social housing dwellings, or adapting the surrounding space for that purpose (removal of some existing buildings or its parts of in order to create additional service facilities space). 2) The wider housing area of social housing complexes should be heterogeneous in structure and form. This can be achieved trough: fragmental integrating of social housing dwellings in existing residential areas or areas of mixed-use; or revitalization of existing social housing complex by introducing different form and structure in a way to affect the homogeneity of the existing residential areas.

Better living conditions in social housing complexes achieved with the increase of quality of the immediate housing surrounding contribute to the better integration of their tenants and the increase of social cohesion, which have a direct impact on the quality of the area but also brings a lot of additional benefits to the society as a whole.

\section{References}

1. J. Jacobs, The Death and Life of Great American Cities (Random House, New York, 1961)

2. T. Kauko, Journal of Housing and Built Environment, 21, 159-176 (2006)

3. O. Newman, Defensible space (MacMillan, New York, 1970)

4. W. Wilson, S. Fainstein, S. Cambell, "The truly Disadvantaged: The hidden agenda". Reading the urban Theory (Blackwell Publishier, Oxford, 1996)

5. G. Bolt, Journal of Housing and the Built Environ, 24, 397-405 (2009)

6. K. Cabernite, Community service through architecture: Social housing with identity (Cigagna University of South Florida, 2009)

7. P. R. Geraedts, T. Voordt, Proceedings of International conference Sustainable urban areas, Roterdam, 4, 23-31 (2007)

8. F. Thebaud, J. Haffner, E. Guerra, Privately-Funded Public Housing Redevelopment: A Study of the Transformation of Columbia Point (Institute for International Urban Development Cambridge, Masachusets, USA, 2008)

9. V. Milić, Urbanistički aspekti socijalnog stanovanja, (Arhitektonski fakultet univerziteta u Beogradu, Beograd, 2006)

10. S.Munch, Journal of the Housing and the Built Environ, 24, 441-455 (2009)

11. G. Radovic, V. Murgul, N.I. Vatin, Applied Mechanics and Materials, 584-586, 564569 (2014)

12. G. Radovic, V. Murgul, N. Vatin, Applied Mechanics and Materials, 641-642, 634638 (2014)

13. J. Ćetković, M. Knežević, M. Žarković, V. Murgul, N. Vatin, Applied Mechanics and Materials, 638-640, 2465-2470 (2014) 